ఠ

\title{
Significant increment in the prevalence of overweight and obesity documented between 1994 and 2008 in Mexican college students
}

This article was published in the following Dove Press journal:

Diabetes, Metabolic Syndrome and Obesity:Targets and Therapy 16 April 2010

Number of times this article has been viewed

\author{
H García-Alcala' \\ D Cuevas-Ramos ${ }^{2}$ \\ Ch Genestier-Tamborero' \\ O Hirales-Tamez' \\ P Almeda-Valdés ${ }^{2}$ \\ R Mehta ${ }^{2}$ \\ CA Aguilar-Salinas ${ }^{2}$
}

'Universidad Popular Autónoma del Estado de Puebla, Puebla, Mexico; ${ }^{2}$ Department of Endocrinology, Instituto Nacional de Ciencias Medicas y Nutricion "Salvador Zubiran" (INCMNSZ), Mexico City, Mexico
Correspondence: Carlos A Aguilar-Salinas Instituto Nacional de Ciencias Medicas y Nutricion "Salvador Zubiran" Vasco de Quiroga I5, Seccion XVI,Tlalpan I4000 Mexico City, Mexico

Tel +52 5555 I3389 I

Fax +52 55 55133891

Email caguilarsalinas@yahoo.com

\begin{abstract}
We describe the changes in the prevalence of overweight and obesity in 4606 students that applied to a Mexican University during 1994 to 2008. The mean ( \pm standard deviation [SD]) age was $17.7 \pm 1.2$ years-old. Progressive and significant increments of bodyweight (female $[\mathrm{F}]=2.6, P=0.03)$, body mass index (BMI) $(\mathrm{F}=4.4, P=0.001)$, and waist circumference $(\mathrm{F}=30.08, P<0.0001)$ in women, and bodyweight (male $[\mathrm{M}]=8.9, P<0.001$ ), BMI $(\mathrm{M}=10.4, P<0.001)$, and waist circumference $(\mathrm{M}=13.01, P<0.001)$ in men were observed. A significant increment $(P<0.05)$ in the prevalence of overweight since 1994 $(\mathrm{n}=87,12.1 \%)$ throughout $1997(\mathrm{n}=102,14.1 \%), 1998(\mathrm{n}=133,18.4 \%), 1999(\mathrm{n}=1993$, $26.8 \%)$, and $2008(\mathrm{n}=206,19.9 \%)$ was documented. Similarly, the prevalence of obesity had a significant increment in all students evaluated $(P<0.0001)$ since $1994(\mathrm{n}=29,13.2 \%)$ through $1997(\mathrm{n}=11,5.0 \%), 1998(\mathrm{n}=45,20.5 \%), 1999(\mathrm{n}=53,24.1 \%)$, and $2008(\mathrm{n}=82$, $37.3 \%)$. The increment was significant in both women $(P=0.02)$ and men $(P<0.001)$. In summary, we report a significant increment in the prevalence of overweight and obesity in Mexican students living in an urban setting over a time period of 14 years.
\end{abstract}

Keywords: body mass index, adolescents, weight problems, obese

\section{Introduction}

The prevalence of obesity is increasing rapidly worldwide ${ }^{1}$ and this is especially true for Latin American countries. The prevalence of overweight and obesity in Mexico showed a progressive increase documented since 1988. National surveys undertaken in Mexico reported an increasing prevalence for overweight $(16.4 \%$ to $40 \%)$ and obesity (18.7\% to 30\%) from 1988 to $2006 .{ }^{2,3}$ Thus, the prevalence in Mexico of overweight and obesity in 2006 was reported as 70\% (about 77 million habitants affected). ${ }^{3}$ Nowadays, the weight problems also affect adolescents, with $29 \%$ of youth aged 10 to 19 years classified as either overweight or obese ${ }^{6}$ and $24 \%$ of MexicanAmerican children classified as overweight. ${ }^{4,5}$ Although obesity is caused by many different factors (including genetics, changes in behavior, culture or environment) the continuous increase of its prevalence has been attributed to changes in dietary patterns and lifestyles. ${ }^{6,7}$ The adoption of diets with a high content of saturated fat and simple carbohydrates; reduced levels of physical activity, increased use of alcohol and tobacco together with increased psychosocial stress, are among the determinants of obesity and other chronic degenerative diseases, particularly in the rapidly growing cities of developing countries. Obesity increases the risk for heart disease and is associated with other chronic diseases including: hyperlipidemia; hyperinsulinemia; hypertension; and early atherosclerosis. ${ }^{8-11}$ Even in childhood, obesity is associated with a variety of 
adverse health consequences that can include: type 2 diabetes; ${ }^{12}$ hypertension and dyslipidemia; ${ }^{12}$ asthma and sleep apnea; ${ }^{13}$ early maturation (that has been associated with overweight that may persist after the completion of biological growth and development); ${ }^{14,15}$ lower self-esteem; ${ }^{16}$ and psychosocial stress. ${ }^{16}$ In addition, adolescents with impaired fasting glucose have an increased number of cardiovascular risk factors, including overweight and abdominal obesity. ${ }^{17,18}$

The information given by studies in socially homogeneous populations are useful to assess the changes occurring in the prevalence of overweight and obesity influenced by the modifications of economic and cultural factors. However, the current information related with weight problems in Mexican adolescents is limited., ${ }^{4,5}$ Therefore, we aimed to evaluate the clinical and biochemical impact of changes in the prevalence of overweight and obesity between 1994 and 2008 in a well-defined urban sample of students.

\section{Methods and procedures}

This is a series of cross-sectional studies undertaken in 1994, 1997, 1998 and 2008, and which included 4606 students of the Universidad Popular Autonoma of Puebla in Mexico. Every student was evaluated at the time of admission to the University. The medical history was recorded using a standardized questionnaire with the student's bodyweight, height, body mass index (BMI), waist circumference and fasting glucose were determined. Assessments were made over the years in which all students could be evaluated, the research team was available and the medical personnel were standardized for the measurement of bodyweight, height, and waist circumference. Throughout study duration there was no additional nutrition or fitness intervention for the students. In addition, students were of similar medium-high socioeconomic status and the admission criteria did not change throughout study duration. The study was approved by the college, and informed consent was obtained from all subjects.

\section{Clinical evaluation}

Students were cited in the morning, one day of the week, after an 8- to 12-hours fast. Participants removed their shoes and upper garments before bodyweight was measured, on a calibrated floor scale, with a maximum measuring capacity of 140-kg (1631 solar scale, Tanita Corp, Tokyo, Japan). The same equipment was used throughout the study. In addition, the same specialized medical personnel that were trained before of each year of the evaluation and using the same technique they undertook the measurements. Bodyweight was measured and recorded to the nearest $0.1 \mathrm{~kg}$. All subjects were instructed to stand in the center of the scale during weight assessment. Height was obtained using the floor scale's stadiometer, again with the student standing on the central part of the scale. Height was measured to the nearest $0.5 \mathrm{~cm}$. BMI was calculated as bodyweight $(\mathrm{kg})$ divided by height $(\mathrm{m})$. Overweight and obesity were defined as a BMI $\geq 25$ and $\geq 30 \mathrm{~kg} / \mathrm{m}$, respectively, for a population that were $>18$ years old. For younger students ( $<18$ years old) we used the Centers for Disease Control and Prevention (CDC) BMI-for-age weight status categories. Overweight was defined being between the 85 th to less than the 95 th percentile, and obesity when the result were equal to or greater than 95th percentile. ${ }^{19}$ Abdominal circumference was measured to the nearest $0.1 \mathrm{~cm}$ at the level of the greatest frontal extension of the abdomen between the bottom of the rib cage and the top of the iliac crest. ${ }^{20}$ All measurements were done by specialized medical personnel that were standardized every year before the evaluation.

\section{Biochemical evaluation}

All analytic measurements were carried out in the central laboratory of the University Hospital. Glucose was measured using the glucose-oxidase method (Boehringer Mannheim, Mannheim, Germany) with a $5 \mathrm{ml}$. sample obtained from antecubital vein. All samples were analyzed the same day. The equipment was regularly calibrated using reference samples provided by the manufacturer. Impaired fasting glucose was defined as $\geq 110 \mathrm{mg} / \mathrm{dL}^{21}$

\section{Statistical analysis}

Normally distributed data, determined using KolmogorovSmirnov test, were expressed as means and standard deviation $( \pm \mathrm{SD})$. Categorical variables were represented by frequency and percentage. Prevalence was calculated with number of existing cases on a specific date/number of people in the population on this date. Linear by linear association chi-square was used for testing if the prevalence of overweight and obesity had a significant change throughout years. One-way ANOVA were used for comparison between means of bodyweight, BMI and waist circumference throughout 1994 to 2008. Post-hoc analyses using Games-Howell test (since variances were not equal) was used to evaluate differences between years. Homogeneity of variance was evaluated with Levene's test. All reported $P$ values are based on twosided tests considering $\leq 0.05$ as significant. All analyses were performed with SPSS 15.0 (Chicago, IL). 


\section{Results}

The clinical and biochemical characteristics of the participants (1991 male and 2615 female) are presented in Table 1. The students aged 15-20 years, and remained without significant variation in every year in both women (17.8 \pm 1.2 years), and men (17.7 \pm 1.4 years). Progressive and significant increments of bodyweight $(3.6 \mathrm{~kg}$
$P=0.005)$, BMI $(10.4 P<0.001)$, and waist circumference ( $27.3 \mathrm{~cm} P<0.001)$ were seen in the whole study population (Table 2). Post-hoc analysis showed a significant increment in bodyweight between 1994 and $1999(P=0.04)$, and 1994 and $2008(P=0.002)$. In the same way, progressive increments in BMI and waist circumference were seen during every year $(P<0.001)$.

Table I Clinical and biochemical characteristics of the 4606 Mexican students recruited in this study

\begin{tabular}{|c|c|c|c|c|c|c|c|c|}
\hline \multirow[t]{2}{*}{ Men } & & \multicolumn{7}{|l|}{ Year } \\
\hline & & 1994 & 1997 & 1998 & 1999 & 2008 & Total & $P^{*}$ \\
\hline \multirow[t]{7}{*}{ LEAN } & $\mathrm{n}(\%)$ & 221 & 150 & 473 & 386 & 293 & 1523 & - \\
\hline & $\begin{array}{l}\text { Age } \\
(\text { mean } \pm \text { SD) }\end{array}$ & $17.6 \pm 1.5$ & $18.3 \pm 0.8$ & $17.3 \pm 1.5$ & $17.3 \pm 1.5$ & $18.2 \pm 0.7$ & $17.6 \pm 1.4$ & NS \\
\hline & Weight (Kg) & $61.6 \pm 8.7$ & $63.0 \pm 7.9$ & $61.3 \pm 7.9$ & $62.1 \pm 7.9$ & $63.4 \pm 7.7$ & $62.1 \pm 8.0$ & NS \\
\hline & Height $(\mathrm{cm})$ & $1.70 \pm 0.07$ & $1.72 \pm 0.06$ & $1.70 \pm 0.07$ & $1.71 \pm 0.06$ & $\mathrm{I} .7 \mathrm{I} \pm 0.06$ & $1.71 \pm 0.06$ & NS \\
\hline & BMI $\left(\mathrm{Kg} / \mathrm{m}^{2}\right)$ & $21.0 \pm 2.1$ & $21.1 \pm 2.0$ & $21.0 \pm 2.1$ & $21.1 \pm 2.1$ & $21.4 \pm 1.9$ & $21.1 \pm 2.1$ & NS \\
\hline & $W C(\mathrm{~cm})$ & $76.4 \pm 6.7$ & $76.3 \pm 5.9$ & $75.7 \pm 6.6$ & $76.4 \pm 6.5$ & $78.0 \pm 6.2$ & $76.5 \pm 6.5$ & NS \\
\hline & $\begin{array}{l}\text { Glucose } \\
(\mathrm{mmol} / \mathrm{l})\end{array}$ & $4.9 \pm 0.59$ & $5.1 \pm 0.6$ & $5.0 \pm 0.5$ & $4.9 \pm 0.5$ & $4.9 \pm 0.3$ & $5.0 \pm 0.5$ & NS \\
\hline \multirow[t]{7}{*}{ OW/OB } & n (\%) & 58 & 58 & 106 & 117 & 129 & 468 & - \\
\hline & $\begin{array}{l}\text { Age } \\
(\text { mean } \pm \text { SD) }\end{array}$ & $17.7 \pm 1.4$ & $18.3 \pm 1.0$ & $17.6 \pm 1.6$ & $17.5 \pm 1.3$ & $18.2 \pm 0.8$ & $17.8 \pm 1.3$ & NS \\
\hline & Weight (Kg) & $81.0 \pm 11.4$ & $81.7 \pm 9.7$ & $82.1 \pm 12.5$ & $83.8 \pm 10.3$ & $84.1 \pm 11.2$ & $83.4 \pm$ II.I & $<0.001$ \\
\hline & Height (cm) & $1.70 \pm 0.07$ & $1.74 \pm 0.06$ & $1.70 \pm 0.07$ & $1.72 \pm 0.06$ & $1.71 \pm 0.05$ & $1.71 \pm 0.06$ & NS \\
\hline & BMI $\left(\mathrm{Kg} / \mathrm{m}^{2}\right)$ & $27.7 \pm 2.5$ & $27.3 \pm 2.0$ & $28.2 \pm 3.5$ & $27.7 \pm 2.4$ & $28.7 \pm 3.4$ & $28.0 \pm 3.0$ & 0.001 \\
\hline & $W C(\mathrm{~cm})$ & $89.4 \pm 8.7$ & $90.1 \pm 8.7$ & $91.3 \pm 11.3$ & $91.8 \pm 9.5$ & $94.3 \pm 9.6$ & $91.7 \pm 9.9$ & $<0.001$ \\
\hline & $\begin{array}{l}\text { Glucose } \\
(\mathrm{mmol} / \mathrm{l})\end{array}$ & $5.0 \pm 0.4$ & $5.1 \pm 0.4$ & $5.2 \pm 0.4$ & $5.0 \pm 0.4$ & $5.0 \pm 0.5$ & $5.1 \pm 0.4$ & NS \\
\hline \multicolumn{9}{|l|}{ Women } \\
\hline \multirow[t]{7}{*}{ LEAN } & n (\%) & 307 & 264 & 420 & 538 & 518 & 2047 & - \\
\hline & $\begin{array}{l}\text { Age } \\
(\text { mean } \pm \text { SD) }\end{array}$ & $18.2 \pm 1.5$ & $18.1 \pm 0.75$ & $18.0 \pm 1.0$ & $17.9 \pm 1.3$ & $18.0 \pm 0.6$ & $17.8 \pm 1.1$ & NS \\
\hline & Weight (Kg) & $53.1 \pm 6.4$ & $53.5 \pm 6.6$ & $54.1 \pm 6.6$ & $54.1 \pm 6.3$ & $53.4 \pm 6.2$ & $53.7 \pm 6.4$ & NS \\
\hline & Height (cm) & $1.57 \pm 0.06$ & $1.59 \pm 0.06$ & $1.59 \pm 0.06$ & $1.58 \pm 0.06$ & $1.58 \pm 0.05$ & $1.58 \pm 0.06$ & NS \\
\hline & BMI $\left(\mathrm{Kg} / \mathrm{m}^{2}\right)$ & $21.3 \pm 2.1$ & $21.0 \pm 2.1$ & $21.2 \pm 2.0$ & $21.5 \pm 1.9$ & $21.3 \pm 2.0$ & $21.3 \pm 2.0$ & NS \\
\hline & $W C(\mathrm{~cm})$ & $69.9 \pm 5.6$ & $69.4 \pm 6.3$ & $70.6 \pm 6.3$ & $72.0 \pm 6.4$ & $73.2 \pm 6.1$ & $71.4 \pm 6.3$ & NS \\
\hline & $\begin{array}{l}\text { Glucose } \\
(\mathrm{mmol} / \mathrm{l})\end{array}$ & $4.8 \pm 0.6$ & $4.9 \pm 0.5$ & $5.0 \pm 0.4$ & $4.6 \pm 0.5$ & $4.7 \pm 0.4$ & $4.8 \pm 0.5$ & NS \\
\hline \multirow[t]{7}{*}{ OW/OB } & n (\%) & 79 & 64 & 92 & 162 & $17 \mid$ & 568 & - \\
\hline & $\begin{array}{l}\text { Age } \\
(\text { mean } \pm S D)\end{array}$ & $17.8 \pm 1.5$ & $18.0 \pm 0.6$ & $18.0 \pm 0.8$ & $17.7 \pm 1.2$ & $|8| \pm 0.6$. & $17.8 \pm 1.1$ & NS \\
\hline & Weight (Kg) & $68.5 \pm 8.4$ & $70.2 \pm 6.5$ & $72.7 \pm 9.9$ & $71.0 \pm 9.3$ & $71.7 \pm 11.8$ & $71.0 \pm 9.9$ & 0.03 \\
\hline & Height (cm) & $1.57 \pm 0.06$ & $1.59 \pm 0.06$ & $1.60 \pm 0.07$ & $1.59 \pm 0.06$ & $1.58 \pm 0.06$ & $1.59 \pm 0.06$ & NS \\
\hline & BMI $\left(\mathrm{Kg} / \mathrm{m}^{2}\right)$ & $27.6 \pm 2.4$ & $27.5 \pm 2.0$ & $28.3 \pm 3.0$ & $28.9 \pm 3.1$ & $29.0 \pm 3.7$ & $28.6 \pm 3.1$ & 0.001 \\
\hline & WC $(\mathrm{cm})$ & $82.2 \pm 7.1$ & $82.0 \pm 6.5$ & $83.8 \pm 8.6$ & $84.1 \pm 8.4$ & $88.3 \pm 9.2$ & $84.8 \pm 8.6$ & $<0.001$ \\
\hline & $\begin{array}{l}\text { Glucose } \\
(\mathrm{mmol} / \mathrm{l})\end{array}$ & $5.1 \pm 1.3$ & $5.0 \pm 1.4$ & $5.0 \pm 0.4$ & $4.7 \pm 0.5$ & $4.9 \pm 0.8$ & $4.9 \pm 0.8$ & NS \\
\hline
\end{tabular}

Note: $* P$ values from a one-way ANOVA.

Abbreviations: OW, overweight; OB, obese; BMI, body mass index; WC, waist circumference; NS, not significant. 
Table 2 Weight, BMI, and waist circumference values in the population studied $(n=4606)$ between 1994 and 2008

\begin{tabular}{llllll}
\hline Year & Age (years) & Weight $(\mathbf{k g})$ & BMI $\left(\mathbf{k g} / \mathbf{m}^{2}\right)$ & WC $(\mathbf{c m})$ & Glucose $(\mathbf{m m o l} / \mathbf{l})$ \\
\hline 1994 & $17.9 \pm 1.3$ & $60.2 \pm 11.5$ & $22.5 \pm 3.4$ & $75.1 \pm 9.1$ & $4.9 \pm 0.7$ \\
1997 & $18.2 \pm 0.8$ & $61.4 \pm 12.2$ & $22.5 \pm 3.4$ & $75.4 \pm 9.4$ & $5.0 \pm 0.7$ \\
1998 & $17.7 \pm 1.3$ & $61.5 \pm 11.8$ & $22.4 \pm 3.6$ & $75.9 \pm 9.6$ & $5.0 \pm 0.4$ \\
1999 & $17.5 \pm 1.3$ & $61.7 \pm 11.8$ & $22.8 \pm 3.5$ & $77.0 \pm 9.4$ & $4.9 \pm 0.5$ \\
2008 & $17.1 \pm 0.71$ & $62.4 \pm 13.2$ & $23.3 \pm 4.0$ & $79.2 \pm 10.3$ & $4.9 \pm 0.53$ \\
Total & $17.7 \pm 1.2$ & $61.6 \pm 12.2$ & $22.7 \pm 3.6$ & $76.8 \pm 9.8$ & $4.9 \pm 0.5$ \\
$P$ value & NS & $P<0.0001$ & $P<0.0001$ & $P<0.0001$ & NS \\
\hline
\end{tabular}

Notes: Data expressed in mean \pm standard deviation. $P$ value is obtained from one way ANOVA for the change of each variable through years.

Abbreviations: BMI, body mass index; WC, waist circumference; NS, not significant.

\section{Results related to bodyweight, $\mathrm{BMI}$, and waist circumference in women}

Analyses grouped by gender showed a significant increment of BMI (F = 4.4, $P=0.001)$, bodyweight $(\mathrm{F}=2.6 P=0.03)$ and waist circumference $(\mathrm{F}=30.08 P<0.0001)$ in women (Figure 1). A significant change was observed when the mean bodyweight in 1994 was compared with the results obtained in $1999(P=0.03)$ and $2008(P=0.05)$. Similar results were seen for the BMI in $1997(P=0.006), 1998(P=0.04)$ and 1999 $(P=0.01)$ as compared to 2008 . The most significant results in women were seen with the change in waist circumference throughout 1994 to 2008 (all $P<0.0001$, Figure 1).

\section{Results related to bodyweight, $\mathrm{BMI}$, and waist circumference in men}

The change in mean bodyweight $(\mathrm{F}=8.9 P<0.001)$, BMI $(\mathrm{F}=10.4, P<0.001)$ and waist circumference (F $=13.01 P<0.001)$ was also significant in males. Individual post-hoc comparisons showed a significant increment in bodyweight from $1994(P<0.001), 1998(P<0.001)$ and $1999(P=0.009)$ compared with 2008 (Figure 1). However, the change in mean bodyweight from 1997 to 2008 was not significant $(P=0.9)$. The BMI also had a significant increment in males in every year from 1994 (all $P<0.001$ ) except in 1997 compared with $2008(P=0.07)$, where only a trend was identified (Figure 1). Similarly, the waist circumference showed a significant increment in males from 1994 through 2008 (all $P<0.001$, Figure 1).

\section{Results related to the prevalence of overweight and obesity}

We observed a significant increment in the prevalence of overweight and obesity from 1994 to 2008. Linear by linear association in the whole study population showed a significant increment $(P=0.05)$ in the prevalence of overweight since $1994(\mathrm{n}=108,12.1 \%)$ throughout $1997(\mathrm{n}=111,13.6 \%)$, $1998(\mathrm{n}=153,18.7 \%), 1999(\mathrm{n}=227,27.8 \%)$, and $2008(\mathrm{n}=$ $218,26.8 \%)$. The increment in the prevalence of overweight were not significant in women; however, results showed a trend $(P=0.07)$. A progressive and significant $(P=0.001)$ increment in the frequency of overweight was seen in men (Figure 2).

Similarly, the prevalence of obesity had a significant increment in all students evaluated $(P<0.0001)$ since 1994 $(\mathrm{n}=29,13.2 \%)$ through $1997(\mathrm{n}=11,5.0 \%), 1998(\mathrm{n}=45$, 20.5\%), $1999(\mathrm{n}=53,24.1 \%)$, and $2008(\mathrm{n}=82,37.3 \%)$. The increment was significant in both women $(P=0.02)$ and men $(P<0.001$, Figure 2$)$.

The mean glucose concentration did not show a significant change in the whole study population $(P=0.90)$ and neither in men $(P=0.99)$ nor in women $(P=0.88)$. The prevalence of abnormal fasting glucose $(\mathrm{n}=525,11.4 \%)$ and diabetes mellitus ( $\mathrm{n}=9,0.2 \%$ ) remained stable throughout years.

\section{Discussion}

The study describes the changes in the prevalence of overweight and obesity in a large representative sample of students from an urban region of Mexico. Every year, this University admits approximately 400 to 700 students. In our sample, $50 \%$ of the participants were born in Puebla and the remaining students in other states of the country. However, 95.2\% of the students lived permanently in Puebla during the study period. Therefore, the majority of the students were exposed to similar environmental factors and experienced comparable modifications in physical activities, nutrition and education during this time period. By comparing the anthropometric and biochemical measurements carried out at the beginning and throughout the years of the study we can assess the influence of the environment on body composition and bodyweight. Interestingly, a progressive increment in bodyweight, BMI and waist circumference were identified in the population studied. The reported changes in body composition produce a 


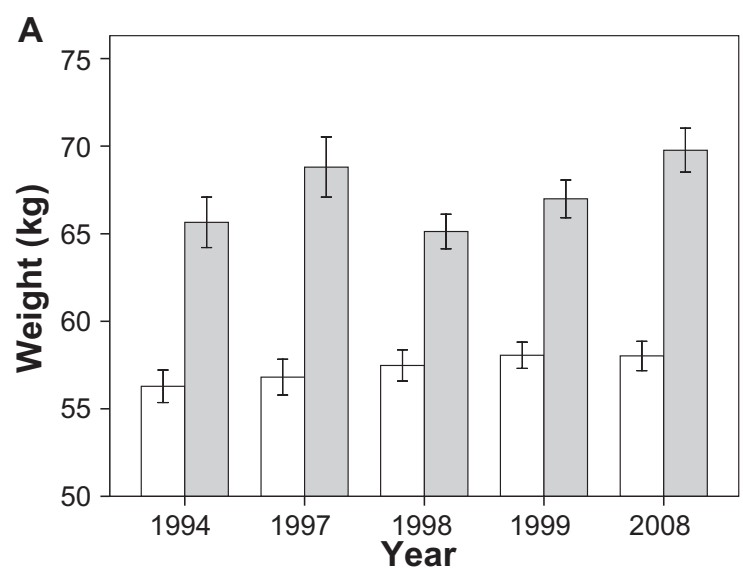

B
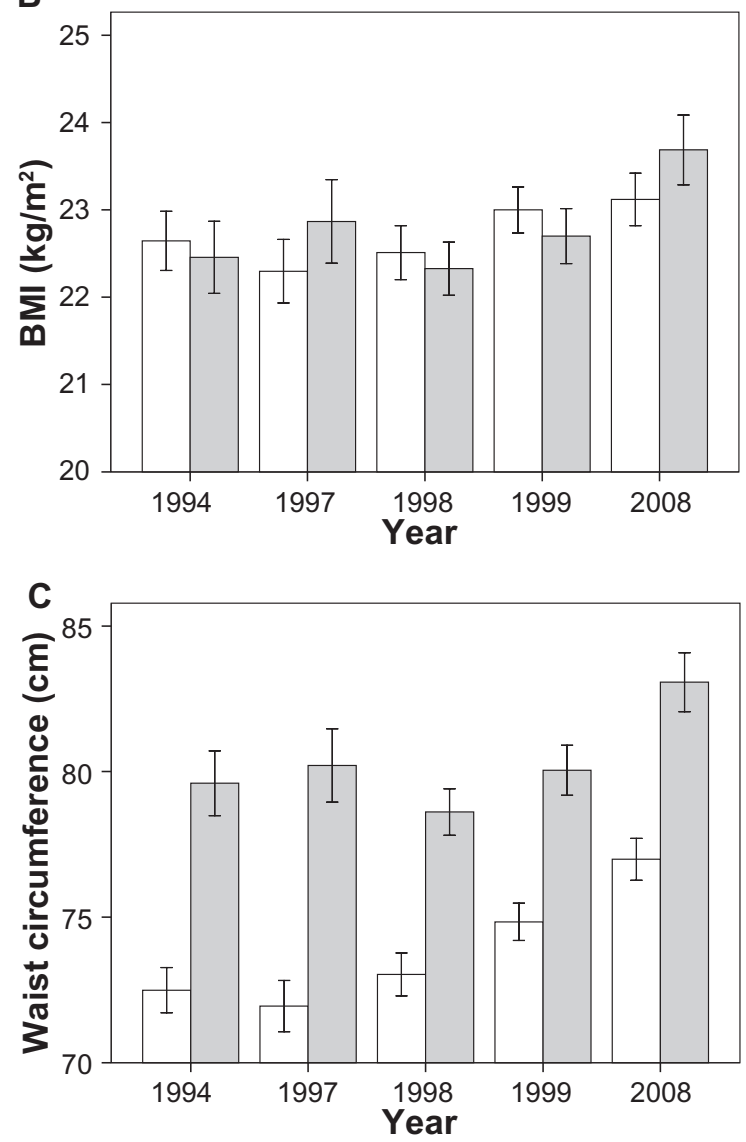

Figure I Mean weight A, BMI B and waist circumference $\mathbf{C}$ of the men (gray) and women (white) studied between 1994 and 2008.

Error bars represent C195\%. Women: weight 1994 vs $1999(P=0.03)$ and 2008 $(P=0.05)$; BMI $1997(P=0.006), 1998(P=0.04)$ and $1999(P=0.0 \mathrm{I})$ vs 2008 and waist circumference 1994 throughout 2008 all $P<0.0001$. Men: weight 1994 $(P<0.00 \mathrm{I})$, I $998(P<0.00 \mathrm{I})$ and $\mathrm{I} 999(P=0.009)$ vs 2008 ; BMI and waist circumference 1994 throughout 2008 (all $P<0.00$ I) (except weight 1997 vs $2008, P=0.07$ ).

significant two-fold increase in the prevalence of overweight (12.1 to $26.8 \%$ ) and a three-fold increase in the prevalence of obesity (13.2 to $37.3 \%)$ over the 14 -year period.

Our data is in agreement with the growing obesity epidemic in adolescents in Hispanic populations. Between 1974 and 1989 , data from population surveys or studies carried out in

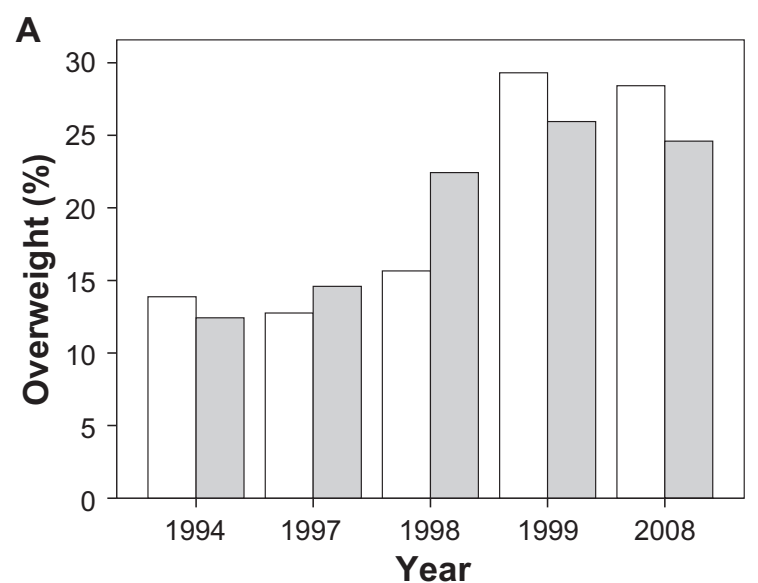

в

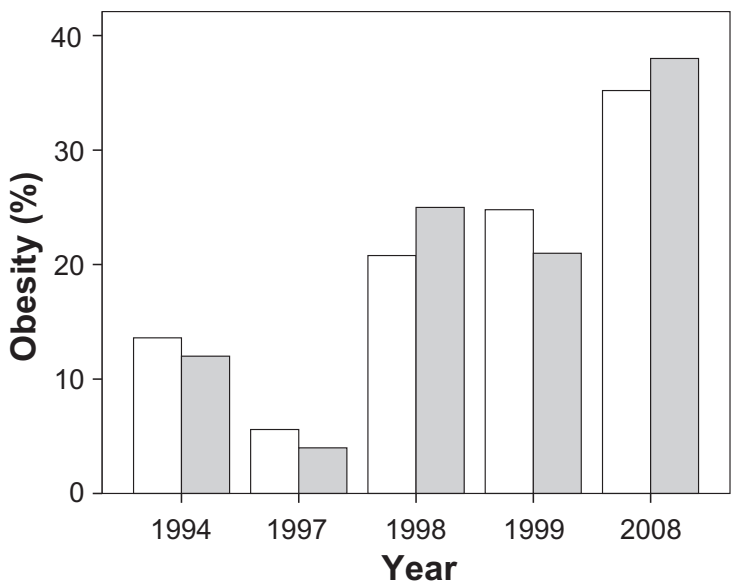

Figure 2 Prevalence of overweight and obesity in men (gray) and women (white) between 1994 and 2008.

Brazil $, 22,23$ Costa-Rica, ${ }^{24}$ certain Caribbean countries, ${ }^{25}$ Chile $^{26}$ and $\mathrm{Mexico}^{27}$ all showed that obesity increased in adults but not in children. However, recent population results from Mexico (1993 to 2006) clearly demonstrate that obesity is increasing not only in adults but also in children and adolescents. ${ }^{28,29}$

The increment in waist circumference in both males and females could be of particular interest. We used a BMI of 25 and $30 \mathrm{~kg} / \mathrm{m}^{2}$ as the cutoffs of overweight and obesity in adults, and the CDC classification for weight problems in students younger than 18 years old. ${ }^{19}$ It is important to consider that the evaluation made in every year was cross-sectional and there was no follow-up for the sample studied. Using these definitions the mean of the bodyweight, BMI, and waist circumference represent one moment evaluation in the students at similar age (Table 1). Thus, we can conclude that the results reported here represent how progressively body composition changed in Mexican adolescents from 1994 through 2008 in an urban setting. Nevertheless, categorizing people based on BMI or BMI percentiles for age and gender on an individual level has the disadvantage that someone with low body fat but very high muscle 
mass may be misclassified as obese (or overweight, if using the pediatric terminology). However, BMI or BMI percentiles on a population level do work fairly well. ${ }^{30}$ Although a significant increment in bodyweight and BMI was observed the change was particularly significant in waist circumference for both males and females. These changes suggest a high prevalence of abdominal obesity that could increase the risk for metabolic diseases in adulthood. Nevertheless, in the sample evaluated we did not identify any significant increment in fasting plasma glucose. Probably, the stress imposed by overweight and obesity in our sample is still well compensated for at this age. However current screening recommendations for fasting blood glucose underestimate the prevalence of impaired glucose metabolism in overweight adolescents. ${ }^{31}$ Similar to our results, fasting plasma glucose was not associated with overweight and obesity in Mexican adolescents in another study. ${ }^{32}$ Therefore, we cannot exclude a progressive deterioration in glucose metabolism if weight problems, inactivity and inadequate diet persist in the following years.

The prevalence of overweight (28.8\%) and obesity (37.3\%) in 2008 in our study, represents an increment of $52.6 \%$ and $65.5 \%$ since 1994. In all students, the prevalence of overweight and obesity in 2008 was $67 \%$, which is $3 \%$ lower than that reported in Mexican adults ${ }^{29}$ and this figure is considerably higher than those found in the US 2003-2004 (NHANES survey). ${ }^{33}$ The prevalence of overweight in our study (28.6\%) was 38\% higher than the prevalence (17.1\%) found in the 2003-2004 NHANES survey $^{33}$ and $26.0 \%$ higher than the prevalence (20\%) in Mexican adolescents of 10 to 17 years old using Centers of Disease Control and Prevention (CDC) and the International Obesity Task Force (IOTF) percentiles. ${ }^{34}$

It is important to mention that in 1997 a lower prevalence of obesity was documented $(5.0 \%)$. Since the same standardized medical personnel did all the evaluations, and all students admitted to the University were evaluated every year, we think that the 1997 data could be the result of chance and a smaller sample size. In the Mexican or Latin American population we did not identify another possible explanation for a decrement in the prevalence of weight problems in 1997. Nevertheless, despite this limitation, the study has identified a significant increment in the frequency of weight problems.

Increments in the prevalence of overweight and obesity among both adults and children have been observed in many countries throughout the world. ${ }^{35}$ The prevalence of obesity among adults in Great Britain almost tripled between 1980 and 2002. ${ }^{36}$ Among preschool children in urban areas of China, the prevalence of obesity increased from 1.5\% in 1989 to $12.6 \%$ in $1997 .{ }^{37}$ In Mexico, since 1926 , there has been a progressive increment in the prevalence of overweight and obesity in various regions. ${ }^{38}$ Thirty eight percent of Hispanic youth (6-18 years) are overweight, which represents twice the national average for US children and 1.7 times greater than that of Mexican-American children in national US surveys. ${ }^{39}$ In the United States, the prevalence of overweight has continued to increase in children and adolescents between 1999 and $2004 .^{33}$ The prevalence of childhood obesity has increased by $182 \%$ in the past 30 years in the $\mathrm{USA}^{.40} \mathrm{~A}$ similar increment in prevalence of childhood and adolescent obesity will occur in Mexico, if appropriate actions are not taken immediately. Our results provide additional proof of the epidemiological transformation that the Mexican population has undergone during the past few decades. ${ }^{3,29,38-41}$ Preventive actions are urgently needed. Although some interventions have been initiated, they usually do not include people younger than 20 years old. ${ }^{42}$ It is important to plan prevention and treatment strategies for children and adults at a national level.

Strengths and limitations of the study must be acknowledged. The results of our study complement the available information regarding the prevalence of overweight and obesity in Mexican adolescents. These data can only be applied to urban, middle-income adolescents based on the characteristics of our study population. Limitations include the cross-sectional nature of the evaluations, the absence of data obtained in other income groups and the lack information on variables related to lifestyle.

In summary, a three-fold increment in the prevalence of obesity and a two-fold increment in the prevalence of overweight were documented between 1994 and 2008 in Mexican adolescents living in an urban setting. This is a risk factor for metabolic diseases that should draw attention to the need to implement programs designed to encourage healthy lifestyles in young individuals.

\section{Disclosures}

Authors declare that they have no conflict of interest relevant to this study.

\section{References}

1. World Health Organization. Obesity: preventing and managing the global epidemic. Report of a WHO consultation, Geneva, 3-5 Jun 1997. Geneva: WHO 1998.

2. Olaiz-Fernández G, Rojas R, Barquera S, et al. Encuesta Nacional de Salud 2000. Tomo 2. La salud de los adultos. Cuernavaca, Morelos, México: Instituto Nacional de Salud Pública; 2003.

3. Olaiz-Fernández G, Rivera-Domenaco J, Shamah-Levy T, et al. Encuesta Nacional de Salud y Nutrición 2006. Cuernavaca, México: Instituto Nacional de Salud Pública; 2006.

4. Villanueva J, Ramírez E. Factores asociados al sobrepeso en estudiantes de 8 a 18 años de áreas suburbanas, Hidalgo, México. Salus cum positum vital. 2004;5:3. 
5. Martorell R, Kettel L, Morgen LH, Laurence MGS. Obesity in Latin American women and children. J Nutr. 1998;128:1464-1473.

6. World Health Organization [homepage on the internet]. World Report in Obesity and Overweight. [updated 2009 October 23; cited 2009 October 29]. Available from: http://www.who.int/dietphysicalactivity/ publications/facts/obesity/en/. Accessed October, 2009.

7. Weiss R, Dziura J, Burgert TS, et al. Obesity and the metabolic syndrome in children and adolescents. New Engl J Med. 2004;350:2362-2374.

8. Berenson GS, Srinivasan SR, Wattigney WA, Harsha DW. Obesity and cardiovascular risk in children. Ann NY Acad Sci. 1993;669:93-103.

9. Berenson GS, Srinivasan SR, Bao W, Newman WP, Tracy RE, Wattigney WA. Association between multiple cardiovascular risk factor and atherosclerosis in children and young adults. The Bogalusa heart study. New Engl J Med. 1998;338:1650-1656.

10. Mahoney LT, Burns TL, Stanford W. Coronary risk factors measured in childhood and young adult life are associated with coronary artery calcification in young adults: the Muscatine Study. J Am Coll Cardiol. 1996;27:277-284.

11. Must A, Jacques PF, Dallal GE, Bajema CJ, Dietz WH. Long-term morbidity and mortality of overweight adolescents. A follow-up of the Harvard growth study of 1922 to 1935. New Engl J Med. 1992;327:1350-1355.

12. Freedman DS, Serdula MK, Srinivasan SR, Berenson GS. Relation of circumferences and skinfold thickness to lipid and insulin concentrations in children and adolescents: the Bogalusa Heart Study. Am J Clin Nutr. 1999;69(2):308-317.

13. Leung AK, Robson WL. Childhood obesity. Postgrad Med. 1990;87:123-130.

14. Lee JM, Appugliese D, Kaciroti N, Corwyn RF, Bradley RH, Lumeng JC. Weight status in young girls and the onset of puberty. Pediatrics. 2007;119(3):e624-e630.

15. Bratberg GH, Nilsen TI, Holmen TL, Vatten LJ. Early sexual maturation, central adiposity and subsequent overweight in late adolescence. A four-year follow-up of 1605 adolescent Norwegian boys and girls: the Young HUNT study. BMC Public Health. 2007;7:1-7.

16. French SA, Story M, Perry CL. Self-esteem and obesity in children and adolescents: a literature review. Obes Res. 1995;3:479-490.

17. Lu Q, Fu-Zai Y, Chun-Ming M, et al. Prevalence of impaired fasting glucose and analysis of risk factors in Han adolescents. $J$ Diabetes Complications. 2009;2. Epub ahead of print.

18. Dietz WH. Health consequences of obesity in youth: childhood predictors of adult disease. Pediatrics. 1998;101:518-525.

19. Kuczmarski RJ, Ogden CL, Grummer-Strawn LM, et al. CDC growth charts: United States Adv Data. 2000;314:1-28.

20. Wang J, Thornton JC, Bari S, et al. Comparisons of waist circumferences measured at 4 sites. Am J Clin Nutr. 2003;77:379-384.

21. Cook S, Weitzman M, Auinger P, Nguyen M, Dietz WH. Prevalence of a Metabolic Syndrome Phenotype in Adolescents. Findings From the Third National Health and Nutrition Examination Survey, 1988-1994. Arch Peadiatr Adolesc Med. 2003;157:821-827.

22. Monteiro CA, Mondini L, Medeiros de Souza AL, Popkin BM. The nutrition transition in Brazil. Eur J Clin Nutr. 1995;49:105-113.

23. Schieri R, Coltinho DC, Marilia LM, Recine E, Evenhart JE. High temporal geographic and income variation in body mass index among adults in Brazil. Am J Public Health. 1994;84(5):793-798.

24. Ministerio de Salud. Encuesta Nacional de Nutrición, Antopometría. San José, Costa Rica 1997.
25. Sinha DP. Changing patterns of food, nutrition and health in the Caribbean. Nutr Res. 1995;15:899-938.

26. Atalah E. Análisis de la situación nutricional de la población de Santiago. Rev Med Chile. 1993;121:819-826.

27. Hernandez B, Peterson K, Sobol A, Rivera J, Sepúlveda J, Lezana MA. Sobrepeso en mujeres de 12 a 49 años y niños menores de cinco años en México. Salud Pública de México. 1996;38:178-188.

28. Yamamoto-Kimura L, Posadas-Romero C, Posadas-Sánchez R, Zamora-González J, Cardoso-Saldaña G, Méndez-Ramírez I. Prevalence and interrelations of cardiovascular risk factors in urban and rural Mexican adolescents. Jour Adolesc Healt. 2006;38:591-598.

29. Velázquez O, Rosas M, Lara A, et al. Prevalencia e interrelación de enfermedades crónicas no transmisibles y factores de riesgo cardiovascular en México. Resultados finales de la Encuesta Nacional de Salud (ENSA) 2000. Arch Cardiol Mex. 2005;73:62-73.

30. Field AE, Laird N, Steinberg E, Fallon E, Smega-Janeeh M, Yanovski JA. Which metric of relative weight best captures body fatness in children? Obes Res. 2003;11:1345-1352.

31. Velasquez-Mieyer PA, Cowan PA, Neira CP, Tylavsky F. Assessing the risk of impaired glucose metabolism in overweight adolescents in a clinical setting. $J$ Nutr Health Aging. 2008;12(10):750S-757S.

32. Velasco-Martínez RM, Jiménez-Cruz A, Higuera-Domínguez, Domínguez de la Piedra E, Bacardí-Gascón M. Obesity and Insulin Resistance among Adolescents from Chiapas. Nutr Hosp. 2009;24:187-92.

33. Ogden CL, Carroll MD, Curtin LR, McDowell MA, Tabak CJ, Flegal KM. Prevalence of overweight and obesity in the United States, 1999-2004. JAMA. 2006;295:1549-1555.

34. Río-Navarro BE, Velázquez-Monroy O, Sánchez-Castillo CP, et al. The high prevalence of overweight and obesity in Mexican children. Obes Res. 2004;12:215-223.

35. Wang Y, Monteiro C, Popkin BM. Trends of obesity and underweight in older children and adolescents in United States, Brazil, China and Russia. Am J Clin Nutr. 2002;75:971-977.

36. Rennie KL, Jebb SA. Prevalence of obesity in Great Britain. Obes Rev. 2005;6:11-12.

37. Luo J, Hu FB. Time trends of obesity in preschool children in China from 1989 to 1997. Int J Obes Relat Metab Disord. 2002;26:553-558.

38. Peña Reyes ME, Cárdenas Barahona EE, Cahvich MB, Barragán A, Malina RM. Growth status of children 6-12 years from two different geographic regions of Mexico. Ann Hum Biol. 2002;29:11-25.

39. Mirza NM, Kadow K, Palmer M, Solano H, Rosche C, Yanovski JA. Prevalence of overweight among inner city Hispanic-American children and adolescents. Obes Res. 2004;12:1298-1310.

40. Jolliffe D. Extent of overweight among US children and adolescents from 1972 to 2000. Int J Obes Relat Metab Disord. 2004;28:4-9.

41. Rivera Domenaco J, Shamah LT, Villalpando Hernandez S, et al. Encuesta Nacional de Nutrición 1999. Estado nutricio de niños y mujeres de México. Cuernavaca Morelos México: Instituto Nacional de Salud Pública. 2001.

42. Gobierno del Estado de Puebla. [homepage on the Internet] Updated 2009 October 23; cited 2009 October 23. Available from: www.puebla.gob.mx/puebla/complementos/contenido/plantilla. jsp?pagina $=$ contenido.jsp\&idmenu=12\&seccion=Salud\&id=36174. Accessed October 2009.

Diabetes, Metabolic Syndrome and Obesity: Targets and Therapy

\section{Publish your work in this journal}

Diabetes, Metabolic Syndrome and Obesity: Targets and Therapy is an international, peer-reviewed open-access journal committed to the rapid publication of the latest laboratory and clinical findings in the fields of diabetes, metabolic syndrome and obesity research. Original research, review, case reports, hypothesis formation, expert
Dovepress

opinion and commentaries are all considered for publication. The manuscript management system is completely online and includes a very quick and fair peer-review system, which is all easy to use. Visit $\mathrm{http}: / /$ www.dovepress.com/testimonials.php to read real quotes from published authors. 